\title{
Horizontally Differentiated Store Brands: Production Outsourcing to National Brand Manufacturers
}

\author{
Shun Shindo and Nobuo Matsubayashi \\ Department of Administration Engineering, Faculty of Science and Technology, Keio University, 3-14-1 Hiyoshi, \\ Kohoku-ku, Yokohama 223-8522, Japan \\ Correspondence should be addressed to Nobuo Matsubayashi; nobuo-m@pa2.so-net.ne.jp
}

Received 30 November 2013; Revised 10 March 2014; Accepted 18 March 2014; Published 15 May 2014

Academic Editor: Takashi Matsuhisa

Copyright (C) 2014 S. Shindo and N. Matsubayashi. This is an open access article distributed under the Creative Commons Attribution License, which permits unrestricted use, distribution, and reproduction in any medium, provided the original work is properly cited.

\begin{abstract}
We study a retailer's strategic decision with regard to outsourcing the production of such types of store brands (SBs) to national brand (NB) manufacturers. The wholesale price of NB is assumed to be set by the manufacturer, while that of the SB is assumed to be set by the retailer. When a retailer outsources SB production to an NB manufacturer, the NB manufacturer might suffer from cannibalization due to offering both the SB and the NB, implying that a strategic interaction between the retailer and manufacturer is an important issue. Based on this motivation, we mainly focus on the strategy of a dominant retailer in such a situation and investigate it with a game-theoretic approach. We show that the optimal strategy for the SB retailer sensitively depends on the degree of differentiation between the SB and the NB. In particular, if both products are less differentiated, the retailer benefits from offering only the SB, and, in this case, the retailer should offer its wholesale price, after the manufacturer sets the NB wholesale price. Furthermore, it is shown that the optimal strategies of the retailer are socially efficient, if and only if the SB and the NB are sufficiently differentiated.
\end{abstract}

\section{Introduction}

By supplying new products by dominant retailers, store brands (or private labels or private brands) have attracted great attention. Store brands (SBs) are the goods designed by firms downstream in the distribution, such as retailers; these downstream firms offer manufacturers the production rights to such goods, which are sold under the retailer's brand or a new brand in collaboration with the manufacturer. Generally, by offering SBs, retailers enjoy the following advantages: they can differentiate from competing firms and flexibly and efficiently control the production and sales of such products and can thus earn higher margins than they can with national brands (NBs). Therefore, SBs can be seen in many categories with increasing retailer power. For example, the UK has the largest SB market in Europe, constituting 40 percent of European SB sales (Sternquist [1]). We also note that, in academic literature as well as in practice, SBs often differ greatly from NBs in that NB wholesale prices are set by manufacturers, while SB wholesale prices are set by retailers.
Following this, in this paper, we suppose that wholesale prices of NBs are set by manufacturers, while those of SBs are set by retailers.

In terms of differentiation, SBs, as well as other products, can be classified into two types (Tirole [2]). The more popular type is vertically differentiated SBs, which aims to achieve differentiation through reduced prices by lowering of quality. In other words, they may be positioned as inferior products. Examples of such goods include "Sam's Cola" (sold by Walmart) and "Tesco Value Sugar Cola" (sold by Tesco). These colas can be sold at low prices because the quality is given little consideration. Such SBs, which have dominated in the past, are categorized as first- or second-generation SBs (Sternquist [1]).

Recently, however, the other type of SBs, that is, horizontally differentiated SBs, is becoming more common. This type of SBs is categorized as third- or fourth-generation SBs (Sternquist [1]). Horizontal differentiation is differentiation in consumers' taste and preference, which focuses 
on consumer preference heterogeneity. Examples include the "Brew," an SB beer by 7-Eleven in Japan. The Brew is manufactured by Suntory, which sells a brand-name beer in Japan; the SB beer was outsourced for production by Seven \& I Holdings, which is the parent company of 7-Eleven in Japan. The quality of the Brew is almost equal to Suntory's NB "Kin-Mugi," and it attempts to differentiate in terms of consumer preference from Kin-Mugi; Kin-Mugi is a lager beer, while the Brew is a dry beer. In this manner, SBs are changing from low-price, low-quality goods produced by original equipment manufacturers (OEMs) to high-end goods produced by manufacturers of brand-name products. For example, a shift to high-end SBs has been observed in the UK, where major retailers sell high-end and organic SBs. Tesco's "Finest" and Sainsbery's "Taste the difference" brands have been recognized as two of the top brands in the UK (Sternquist [1]). Moreover, Japanese SBs are transitioning to horizontally differentiated SBs made by NB manufacturers. In fact, leading NB manufacturers in Japan, such as Ajinomoto and Nisshin Seifun Group, have been producing SBs offered by major retailers. Furthermore, in Europe and in the USA, even manufacturers of strongly branded NBs, such as $P \& G$, Unilever, Heinz, Kraft, and Nestle, have been producing SBs (Kumar and Steenkamp [3]). Considering this trend, in this paper, we analyze horizontally differentiated SBs made by NB manufacturers that were offered the production rights by retailers.

The growth of this type of SBs has increased the importance of considering strategic interaction between retailers and manufacturers. Specifically, if a retailer outsources its SB production to an NB manufacturer, then both the retailer and the manufacturer should be concerned with cannibalization between the NB and the SB. In fact, in the early days of SBs, the power of the retailers' SBs was small and, thus, we could not see that the manufacturers change wholesale prices of their NBs in response to the emergence of the retailers' SBs. Recently, however, the power balance has shifted from manufacturers to retailers, allowing retailers' SBs to affect the prices of manufacturers' NBs. For example, in the Japanese beer market mentioned above, Suntory launched Kin-Mugi in 2007 at the price of 135 yen (Suntory [4]). Then, in 2009, Suntory accepted to produce the Brew, and Seven \& I Holdings launched it at 123 yen (Seven \& I [5]). As a result, Suntory was forced to lower the price of Kin-Mugi in 2011 (ranging from 120 to 125 yen), which would imply that its wholesale price has also been lowered (Suntory [6]).

This example suggests that manufacturers are forced to change their NB prices in response to the emergence of retailers' SBs. However, instead of lowering their NB prices, manufacturers may refuse to produce retailers' SBs, if they would suffer from cannibalization with their NBs. In fact, such actions are frequently seen in the real-world markets. For example, in the Japanese beer market, Suntory has announced that it is ceasing production of the SB offered by Aeon, a strong competitor of 7-Eleven (the Sankei Newspaper reported this in March 10, 2010, in Japanese). Further, in Europe and the USA, many major companies including P\&G, Unilever, Coca-Cola, Heineken, and Kellogg have made similar refusals (Boyle [7]). Therefore, retailers should carefully consider manufacturers' reactions, when they outsource the production of their SBs.

Based on this motivation, we explore a strategic interaction between a dominant retailer and an NB manufacturer with regard to production outsourcing of the retailer's SB to the manufacturer in an oligopolistic situation. When influential retailers launch their SBs by offering manufacturers the production rights, how should retailers make decisions about their SBs while taking the manufacturers' reactions into account? To address this question, we develop a gametheoretic model that incorporates the following three key factors: the assortment, the timing of the assortment decision, and the timing of the outsourcing decision, that is, setting of the SB wholesale price. In addition, we investigate the impact of the optimal strategy taken by the SB retailer on manufacturer's profit and social welfare. Specifically, our analysis is devoted to the following four specific questions.

(i) Assuming that there are two horizontally differentiated goods, should a dominant retailer carry both the $\mathrm{SB}$ and the NB, or only the SB?

(ii) When should the retailer set its SB wholesale price? Should the retailer make the decision before or after the manufacturer sets the NB wholesale price?

(iii) If the retailer can also choose the timing of its assortment decision, then when should the retailer make the decision?

(iv) What are the implications of the SB retailer's optimal strategy for the manufacture's profit and social welfare?

We now present an overview of the results obtained in this paper. First, if the SB and the NB are sufficiently differentiated, the retailer should carry both the SB and the $\mathrm{NB}$ and set the SB wholesale price before the manufacturer sets its NB wholesale price. Second, if the two brands are moderately differentiated, the retailer should carry both the $\mathrm{SB}$ and the NB but choose this assortment and set the SB wholesale price after the manufacturer's action. Third, if the two brands are minimally differentiated, the retailer should carry the SB only and set the SB wholesale price after the manufacturer's action. Finally, the retailer's optimal strategies are consistent with both the manufacturer's and the consumers' benefits, if and only if both products are sufficiently differentiated.

The rest of this paper is organized as follows. In Section 2, we review the literature related to our study. In Section 3, we develop our game-theoretic model incorporating assortments and the timing of outsourcing as the SB retailer's strategy. In Section 4, by analyzing the equilibrium outcomes of our game, we derive the optimal strategy for the SB retailer. In Section 5, we discuss the implications of the retailer's optimal strategy in terms of the manufacturer's profit and social welfare. Finally, Section 6 concludes this paper with managerial and social implications. Precise descriptions of the equilibrium outcomes and proofs of all propositions are provided in the Appendix. 


\section{Literature Review}

The literature relevant to our paper primarily concerns the interactions between a manufacturer and a retailer. In particular, we review the relevant literature in terms of three key words: leadership related to the decision of wholesale prices, assortment, and SB.

Examining the order of wholesale price decision, Choi [8] considers two competing manufacturers and only one retailer, which carries each manufacturer's product, and analyzes three channel structures (power balance scenarios): manufacturer-Stackelberg (the manufacturers move first and the retailer second), retailer-Stackelberg (the retailer moves first and the manufacturers second), and verticalNash (all players move simultaneously). Choi [9] develops Choi [8] and considers two competing manufacturers and two competing retailers. More recently, Edirisinghe et al. [10] analyze the stability of each scenario, which Choi [8] presents with regard to the leader position, and discuss the stable structure of decision making. Wu et al. [11] explore some additional scenarios where retailers determine their prices in a Stackelberg fashion. However, in any case, when such manufacturers and retailers make decisions in a decentralized structure, there is the problem of double marginalization (e.g., Spengler [12] and Tirole [2]). This problem can be solved by several means, including vertical integration and coordination schemes, which have been studied in many works, such as McGuire and Staelin [13], Jeuland and Shugan [14], Lee and Staelin [15], Anderson and Bao [16], Karray [17], and Matsui [18]. Unlike these approaches, Majumder and Srinivasan [19] consider a serial supply chain and attempt to solve this problem by changing the leader position of decision making in the supply chain. These studies consider the case in which the retailer is the leader, as in our study. Moreover, Geylani et al. [20] provide implications about the channel strategy a manufacturer should take when there is a dominant retailer who has channel power. We also note that such upward channel decentralization is closely related to an issue of strategic outsourcing (e.g., Cachon and Harker [21], Atkins and Liang [22], Lim and Tan 2010 [23], and Liu and Tyagi [24]). However, because each of these works focuses on the control of the supply chain through pricing, each assumes that each manufacturer produces a single product. Therefore, this paper differs widely from these works in that product assortments are considered.

On the other hand, the literature on product assortment as well as product line design is also relevant to our study. Although most papers in this area focus on the monopolist's product line design in vertical and horizontal differentiation models, incorporating some important factors into models (e.g., Yu [25] considers costs associated with a batch production), some recent papers also explore product line competition (e.g., Matsubayashi et al. [26], Tang and Yin [27], and Lacourbe [28]). While all of these papers do not model a supply chain structure, there are works that address interactions between a manufacturer and a retailer with regard to product assortments. For example, Dukes et al. [29] compare the case in which a manufacturer decides assortments with the case in which a retailer decides them, and they consequently show that the retailer may reduce its assortment when the retailer has the dominant power to determine its assortment. Amrouche and Zaccour [30] investigate a strategic interaction between a manufacturer and a retailer with regard to a shelf-space allocation of NB and SB in a store. More recently, Kurtulus and Toktay [31] focus on the situation in which a single retailer determines the shelf space allocated to the category. They analyze the change, when the player who decides the shelf space is replaced. However, unlike our work, none of those works considers modelling wholesale pricing by retailers, which plays an important role in SB strategies.

Finally, focusing on SB strategy, Quelch and Harding [32] discuss how NBs compete with SBs from a manufacturer perspective and analyze a case study with regard to the SB threat and the character of the NB. Batra and Sinha [33] is an empirical study addressing factors of SB success. However, few works use an analytical model, such as a game-theoretic approach. Mills [34] shows an effect of SB introduction in the sense that it can lead to lowering the wholesale price of NB. Narasimhan and Wilcox [35] investigate the dominant power of a retailer over a manufacturer due to the SB by addressing the difference in consumer segmentation. Kurata et al. [36] consider the channel strategy for a manufacturer's NB when a retailer sells its SB. Karray and Martin-Herran [37] investigate long-term advertising and pricing competition between NB and SB. Heese [38] explores a strategic interaction between monopolistic manufacturer and retailer with regard to a vertical differentiated SB, mainly from manufacturer's perspective. On the other hand, Scott Morton and Zettelmeyer [39] discuss retailer's strategic positioning of SB in a product space. Furthermore, Groznik and Heese [40] explore a situation similar to ours where two competitive retailers decide whether or not to introduce their individual $\mathrm{SB}$ in consideration of a response by a manufacturer who offers its NB. However, none of these works considers the case in which a retailer sells its SB by means of outsourcing production to an NB manufacturer. In this way, the present work differs from the previous literature.

As such, many works analyze the strategic interaction between manufacturer and retailer with regard to the SB supply. However, as far as we know, this paper is the first to assume that a retailer outsources the production of its horizontally differentiated SB to an NB manufacturer. Specifically, this paper is novel in that it discusses decision making of product assortments and wholesale prices by a dominant retailer assuming cannibalization between the SB and the NB of the manufacturer.

\section{Models}

In this section, we develop our game-theoretic model. Specifically, we model three scenarios concerning the decision making of a retailer and then compare them in Section 4.

Let us consider four players, consisting of three retailers (indexed as 1, 2, and 3) and a single manufacturer $M$. Among the three retailers, only retailer 1 can supply an SB to the market. Manufacturer $M$ can produce two products (SB and 
NB) in its product line, which are horizontally differentiated. Manufacturer $M$ offers the NB wholesale price $w_{n}$ to each retailer. The wholesale price $w_{n}$ is the same for each retailer; that is, price discrimination is not considered. In contrast, manufacturer $M$ is not allowed to set the $\mathrm{SB}$ wholesale price $w_{s}$. Instead, retailer 1 sets $w_{s}$. While manufacturer $M$ can distribute the SB to retailer 1 only, it can distribute its $\mathrm{NB}$ to each competing retailer $(1,2$, and 3 ). (We note that although this setting of three retailers unfortunately requires a complicated derivation of equilibrium, it ensures a realistic model where there exists an NB competition even if retailer 1 rejects the $\mathrm{NB}$ in its product line.) Let $q_{s}$ be the amount of SB distributed to retailer 1 , and let $q_{i}$ be the amount of NB distributed to retailer $i=1,2,3$. Each retailer sells this quantity to the market; that is, it is not considered that these products are sold out or unsold. Each product's (SB and NB) retail price is determined by the total quantity in the market. In this paper, we consider a Cournot competition with a linear demand function, which is often used in microeconomics and game theory, and in many relevant works such as Choi [8], Chu and Desai [41], Coughlan [42], Jeuland and Shugan [14], Dukes et al. [29], Kurtulus and Toktay [31], Lee and Staelin [15], and McGuire and Staelin [13]. Specifically, we consider the following inverse demand functions:

$$
\begin{aligned}
& P_{s}\left(q_{s}, q_{1}, q_{2}, q_{3}\right)=1-q_{s}-\beta\left(q_{1}+q_{2}+q_{3}\right), \\
& P_{n}\left(q_{s}, q_{1}, q_{2}, q_{3}\right)=1-\beta q_{s}-\left(q_{1}+q_{2}+q_{3}\right),
\end{aligned}
$$

where $0<\beta<1$. The parameter $\beta$ captures product differentiation between the SB and the NB. The closer $\beta$ is to 0 , the less substitutable (i.e., more horizontally differentiated) are the two products, implying relaxed competition. In contrast, the closer $\beta$ is to 1 , the more substitutable (i.e., less horizontally differentiated) are the two products, implying intense competition. We assume that the NBs offered by the three retailers are perfectly substitutable for consumers. (This assumption is also made in many of the works presented above.) In other words, there is no differentiation among the retailers by location or brand, except that retailer 1 is differentiated in terms of selling an SB to the market.

With respect to retailer 1's options in terms of product assortments, we consider the following two types of assortments. One assortment refers to when retailer 1 carries both the NB and the SB. We denote this assortment by $F$ (Full line). The other assortment refers to when retailer 1 introduces the SB and rejects the NB in its product line. We denote this assortment by $S$ (Single product). An assortment with only the NB can also be considered; however, it can be easily verified that this assortment is strategically dominated by assortment $S$ for any feasible $\beta$. Therefore, we omit this assortment.

For simplicity, we assume that variable production costs are symmetric between the NB and the SB and any fixed/variable cost with regard to an additional assortment is not considered. Therefore, by normalizing all the variable production costs as zero, firm is profit to be maximized, $\pi_{i}$, is specifically described as follows:

$$
\begin{gathered}
\pi_{M}= \begin{cases}w_{n}\left(q_{1}+q_{2}+q_{3}\right)+w_{s} q_{s} & \text { under assortment } F \\
w_{n}\left(q_{2}+q_{3}\right)+w_{s} q_{s} & \text { under assortment } S ;\end{cases} \\
\pi_{1}= \begin{cases}\left(p_{n}-w_{n}\right) q_{1}+\left(p_{s}-w_{s}\right) q_{s} & \text { under assortment } F \\
\left(p_{s}-w_{s}\right) q_{s} & \text { under assortment } S ;\end{cases} \\
\pi_{2}=\left(p_{n}-w_{n}\right) q_{2}, \quad \pi_{3}=\left(p_{n}-w_{n}\right) q_{3} .
\end{gathered}
$$

We now explain the timing of the decision making on which our analysis focuses. Generally, it is known that the decision-making timing is often given by the power balance between a manufacturer and a retailer. When a manufacturer is dominant over a retailer, it is often assumed that the manufacturer moves first. When a manufacturer is as powerful as a retailer, it is often assumed that they move simultaneously. When a retailer is dominant over a manufacturer, it is often assumed that the retailer moves first (Choi [8]). However, as mentioned in Section 1, we consider the situation where there exists a powerful retailer that can choose when it makes its decisions. That is, we assume that retailer 1 can choose whether to offer the SB wholesale price before or after the NB wholesale price is determined, and that manufacturer $M$ accepts the retailer's decision and flexibly reacts to it. Moreover, we assume that retailer 1 is so dominant that it can refuse to sell the NB, that is, choose its assortment, as well as the timing of its decision.

In this regard, we specifically consider the following three scenarios. The first scenario is the ARM scenario (Assortment-Retailer-Manufacturer), in which retailer 1 first decides its assortment and then offers the SB wholesale price, and then manufacturer $M$ sets the NB wholesale price. The second scenario is the AMR scenario (AssortmentManufacturer-Retailer), in which retailer 1 first decides its assortment, then manufacturer $M$ sets the NB wholesale price, and then the retailer offers the SB wholesale price. The last scenario is the MAR scenario (ManufacturerAssortment-Retailer), in which manufacturer $M$ first sets the NB wholesale price, then retailer 1 decides its assortment and then offers the SB wholesale price. If we consider the situation where the $\mathrm{NB}$ is already sold to retailers at some wholesale price, we can interpret these scenarios as the situations where retailer 1 compels manufacturer $M$ to update the NB wholesale price, taking the strategic interaction with the retailer into account. Specifically, the ARM scenario can be interpreted as the situation in which retailer 1 first decides its assortment and offers the SB wholesale price and then compels the manufacturer to update the NB wholesale price. Moreover, the AMR scenario can be interpreted as the situation in which retailer 1 decides its assortment and then compels the manufacturer to change the NB wholesale price, taking the retailer's strategic reaction concerning the SB wholesale price into account. Finally, the MAR scenario can be interpreted as the situation in which the retailer compels the manufacturer to update the NB wholesale price and then decides its assortment and offers the SB wholesale price. In 
what follows, we develop our model for each scenario, with the Stackelberg game reflecting the decision-making order.

3.1. ARM Scenario. For the ARM scenario, the timeline of the game is given as follows. In Stage 1, retailer 1 determines its assortment $F$ or $S$. In Stage 2, it offers the SB wholesale price, $w_{s}$. In Stage 3, manufacturer $M$ decides whether to accept or reject the production of the SB. In Stage 4, manufacturer $M$ sets the NB wholesale price, $w_{n}$. In Stage 5, the three retailers simultaneously choose the quantities of the products they sell.

3.2. AMR Scenario. For the AMR scenario, the time line of the game is given as follows. In Stage 1, retailer 1 determines its assortment $F$ or $S$. In Stage 2, manufacturer $M$ sets the NB wholesale price, $w_{n}$. In Stage 3, retailer 1 offers the SB wholesale price, $w_{s}$. In Stage 4, manufacturer $M$ decides whether to accept or reject the production of the SB. In Stage 5 , the three retailers simultaneously choose the quantities of the products they sell.

3.3. MAR Scenario. For the MAR scenario, the time line of the game is given as follows. In Stage 1, manufacturer $M$ sets the NB wholesale price, $w_{n}$. In Stage 2, retailer 1 determines its assortment $F$ or $S$. In Stage 3, retailer 1 offers the SB wholesale price, $w_{s}$. In Stage 4 , manufacturer $M$ decides whether to accept or reject the production of the SB. In Stage 5, the three retailers simultaneously choose the quantities of the products they sell.

For each scenario, we note that, in the final stage (Stage $5)$, retailer 1 is allowed to set its NB sales quantity as zero $\left(q_{1}=0\right)$, even if it chooses full-line assortment in an earlier stage. Therefore, the precise interpretation of the assortment decision in the earlier stage is that retailer 1 simply determines whether or not to commit to the single-product strategy. In addition, we can obviously see that with regard to retailer 1's decision timing, the order between determining its assortment and offering the SB wholesale price is not essential as long as they are successive stages. In this sense, it is noted that the abovementioned scenarios are the only possible scenarios in our framework. For each scenario, we find the subgame perfect equilibrium of the game by backward induction.

\section{Optimal Strategies for the SB Retailer}

In this section, we compare the equilibria for each of the three scenarios. For each scenario, it is ensured that the equilibrium is uniquely determined, as shown in Appendix A. Based on these equilibrium results, we first compare the ARM scenario with the AMR scenario. That is, given an assortment, we derive retailer 1's optimal timing of the outsourcing decision. Specifically, we show the optimal timing under full-line assortment in Proposition 1 and under a single product in Proposition 2. We then show retailer 1's optimal assortment $(F$ or $S$ ) in Proposition 3. Finally, we consider the MAR scenario and compare it with the other scenarios. By doing so, we derive the optimal timing of the assortment decision for retailer 1 in Proposition 4. By summarizing these
TABLE 1: Comparison between the ARM scenario and the AMR scenario under assortment $F$.

\begin{tabular}{lccc}
\hline & $\begin{array}{c}\text { ARM scenario } \\
\text { under assortment } F\end{array}$ & Gap & $\begin{array}{c}\text { AMR scenario } \\
\text { under assortment } F\end{array}$ \\
\hline$p_{n}$ & Low & $<$ & High \\
$p_{s}$ & Low & $\approx$ & High \\
$w_{n}$ & Low & $<$ & High \\
$w_{s}$ & Low & $\approx$ & High \\
$m_{n}$ & High & $>$ & Low \\
$m_{s}$ & High & $\approx$ & Low \\
$q_{1}$ & High & $>$ & Low \\
$q_{2}\left(=q_{3}\right)$ & High & $>$ & Low \\
$q_{s}$ & Low & $\approx$ & High \\
\hline
\end{tabular}

propositions, we can find the most profitable scenario, that is, the optimal outsourcing strategy for the SB retailer.

4.1. Optimal Timing of the Outsourcing Decision under a Given Assortment. Here, we analyze the optimal timing for retailer 1 to offer the SB wholesale price (either before or after manufacturer $M$ sets the NB wholesale price). We first consider the case under full-line assortment. Specifically, provided that the assortment is determined as $F$ in Stage 1, we compare the ARM scenario and the AMR scenario based on the equilibrium profits obtained from the subsequent stages. As a result, we obtain the following proposition.

Proposition 1. Given assortment $F$, the ARM scenario is more profitable for retailer 1 than the AMR scenario for any $\beta(0<$ $\beta<1)$.

Proposition 1 shows that under full-line assortment, retailer 1 should offer the SB wholesale price before the manufacturer sets the NB wholesale price; that is, the SB retailer should move first. The key to understand this is that this difference between first-move and second-move has more impact on the $\mathrm{NB}$ revenue rather than the $\mathrm{SB}$ revenue. If retailer 1 moves first, then manufacturer $M$ is better off lowering its NB wholesale price to compete with SB. Therefore, retailer 1 can supply enough NB to the market. In contrast, if retailer 1 moves second, then manufacturer $M$ sets a higher NB wholesale price in order to gain a higher margin. Then, retailer 1 attempts to keep the NB retail price high enough to secure a profit margin. Therefore, retailer 1 cannot supply NB in a sufficient quantity. Moreover, in order to avoid a rejection of SB production due to cannibalization with the $\mathrm{NB}$ and maximize the total profit from them, retailer 1 also cannot offer a lower wholesale price and, thus, supplies SB in only that much quantity. For clarity, the comparison of both scenarios in each of the equilibrium outcomes is displayed in Table 1, where $m_{n}$ and $m_{s}$ are retailer 1's margins on the NB and the SB and are defined as $m_{n} \equiv p_{n}-w_{n}$ and $m_{s} \equiv p_{s}-w_{s}$, respectively.

We now consider the situation where the assortment is given as single product in Stage 1. Under assortment $S$, we compare the ARM scenario and the AMR scenario based on 
TABLE 2: Comparison between the ARM scenario and the AMR scenario under assortment $S$.

\begin{tabular}{lccc}
\hline & $\begin{array}{c}\text { ARM scenario } \\
\text { under assortment } S\end{array}$ & Gap & $\begin{array}{c}\text { AMR scenario } \\
\text { under assortment } S\end{array}$ \\
\hline$p_{n}$ & Low & $<$ & High \\
$p_{s}$ & Low & $<$ & High \\
$w_{n}$ & Low & $<$ & High \\
$w_{s}$ & Low & $\approx$ & High \\
$m_{n}$ & High & $>$ & Low \\
$m_{s}$ & Low & $\approx$ & High \\
$q_{2}\left(=q_{3}\right)$ & High & $>$ & Low \\
$q_{s}$ & Low & $\approx$ & High \\
\hline
\end{tabular}

the equilibrium profits obtained from the subsequent stages. As a result, we obtain the following proposition.

Proposition 2. Given assortment $S$, the AMR scenario is more profitable for retailer 1 than the ARM scenario for any $\beta(0<$ $\beta<1)$.

Proposition 2 shows that retailer 1 should offer the SB wholesale price after manufacturer $M$ sets the NB wholesale price; that is, the retailer should move second. This result is in sharp contrast with that of Proposition 1. In this case, it should be noted that retailer 1 does not suffer from cannibalization between the SB and the NB. If manufacturer $M$ moves first, then it sets the NB wholesale price at a higher level, which compels retailers 2 and 3 to maintain a higher retail price so as to secure marginal profits. Therefore, since less quantity of the NB is being supplied in the market, retailer 1 takes advantage of this effect and so can supply SB in enough quantity to the market with a higher profit margin. This socalled "free-riding" effect dominates the advantage of moving first, and, hence, the SB retailer can be more beneficial when it moves second. For clarity, the comparison of both scenarios in each of the equilibrium outcomes is displayed in Table 2.

4.2. Optimal Assortment Strategy. We now consider a decision of assortment by retailer 1 in Stage 1 . That is, we compare the profit at the subgame-perfect equilibrium of the whole game in the ARM scenario with that in the AMR scenario. However, from Propositions 1 and 2, it is sufficient to compare the ARM scenario under assortment $F$ with the AMR scenario under assortment $S$. We immediately obtain the following proposition.

Proposition 3. There necessarily exists some $\beta^{*}\left(0<\beta^{*}<1\right)$ such that

(1) if $0<\beta<\beta^{*}$, then the ARM scenario with assortment $F$ is more profitable;

(2) if $\beta^{*}<\beta<1$, then the AMR scenario with assortment $S$ is more profitable.

Proposition 3 shows that if the SB and the NB are highly differentiated (i.e., if $\beta$ is low), the retailer should set the
TABLE 3: Comparison between the ARM scenario under assortment $F$ and the AMR scenario under assortment $S$, if $\beta$ is low.

\begin{tabular}{lccc}
\hline & $\begin{array}{c}\text { ARM scenario } \\
\text { under assortment } F\end{array}$ & Gap & $\begin{array}{c}\text { AMR scenario } \\
\text { under assortment } S\end{array}$ \\
\hline$p_{n}$ & Low & $<$ & High \\
$p_{s}$ & High & $>$ & Low \\
$w_{n}$ & Low & $<$ & High \\
$w_{s}$ & High & $>$ & Low \\
$m_{n}$ & Low & $<$ & High \\
$m_{s}$ & Low & $<$ & High \\
$q_{s}$ & Low & $<$ & High \\
$q_{s}+q_{1}$ & High & $>$ & Low \\
$q_{2}$ & Low & $<$ & High \\
\hline
\end{tabular}

SB wholesale price before the manufacturer does so for the $\mathrm{NB}$, and the retailer should carry both the SB and the NB. Otherwise (i.e., if $\beta$ is high), the retailer should set the $\mathrm{SB}$ wholesale price after the manufacturer does so for the NB, and the retailer should carry only the SB.

First, we consider the case in which the SB and the NB are highly differentiated. Table 3 shows the comparison of the equilibrium outcomes in each scenario. The result is rather intuitive. Since both products are sufficiently horizontally differentiated, both retailer 1 and manufacturer $M$ need not consider cannibalization between them or give thought to intense competition between the SB and the NB sold by retailers 2 and 3 . As such, the manufacturer can supply enough quantities of both products to the market. Therefore, full-line assortment is superior to the single-product strategy.

On the other hand, for the case in which the SB and the $\mathrm{NB}$ are less differentiated, both retailer 1 and manufacturer $M$ suffer from cannibalization under full-line assortment, which implies that retailer 1 cannot offer a wholesale price that is low enough to avoid rejection of SB production. Moreover, competition between the SB and the NB sold by retailers 2 and 3 is intense, which implies that retailer 1 cannot supply enough of both the NB and the SB in order to keep higher retailing prices. In response, however, the other retailers expand their sales quantities, resulting in excessive reduction in the total sales quantity of retailer 1 in the equilibrium. This inefficiency outweighs the positive effect of enjoying lower NB wholesale price from moving first. Since carrying only the SB can eliminate such inefficiency, it is more profitable. For clarity, the comparison of both scenarios in each of the equilibrium outcomes is displayed in Table 4.

4.3. Optimal Timing of Assortment Decision. To complete the analysis of retailer 1's optimal strategy, we finally investigate the MAR scenario, in which retailer 1 determines its assortment after manufacturer $M$ sets the NB wholesale price. We compare the equilibrium profit in this scenario with the result in Proposition 3. Then, the following proposition is immediately obtained. 
TABLE 4: Comparison between the ARM scenario under assortment $F$ and the AMR scenario under assortment $S$, if $\beta$ is high.

\begin{tabular}{lccc}
\hline & $\begin{array}{c}\text { ARM scenario } \\
\text { under assortment } F\end{array}$ & Gap & $\begin{array}{c}\text { AMR scenario } \\
\text { under assortment } S\end{array}$ \\
\hline$p_{n}$ & Low & $<$ & High \\
$p_{s}$ & High & $>$ & Low \\
$w_{n}$ & Low & $<$ & High \\
$w_{s}$ & High & $>$ & Low \\
$m_{n}$ & High & $>$ & Low \\
$m_{s}$ & Low & $<$ & High \\
$q_{s}$ & Low & $<$ & High \\
$q_{s}+q_{1}$ & Low & $<$ & High \\
$q_{2}$ & High & $>$ & Low \\
\hline
\end{tabular}

Proposition 4. There necessarily exist some $\bar{\beta}$ and $\widehat{\beta}(0<\bar{\beta} \approx$ $\left.\beta^{*}<\widehat{\beta}<1\right)$ such that

(1) if $0<\beta<\bar{\beta}$ or $\widehat{\beta}<\beta<1$, then the most profitable scenario is the same as that in Proposition 3;

(2) if $\bar{\beta}<\beta<\widehat{\beta}$, then the MAR scenario with assortment $F$ is the most profitable.

According to Proposition 4, there exists a case in which it is profitable for retailer 1 to determine its assortment after manufacturer $M$ sets the NB wholesale price (i.e., when $\beta$ lies between $\bar{\beta}$ and $\widehat{\beta}$ ). Otherwise, the assortment-decision timing does not affect retailer l's equilibrium profit and assortment. If $\bar{\beta}<\beta<\widehat{\beta}$, then the optimal assortment changes depending on the decision timing. That is, as seen in Proposition 2, it is profitable to carry only the SB when it determines its assortment before the manufacturer sets the $\mathrm{NB}$ wholesale price. However, if retailer 1 determines its assortment after manufacturer $M$ sets the NB wholesale price, then it is better off with full-line assortment.

In this parameter region, when manufacturer $M$ controls the NB wholesale price by moving first so that the retailer can then choose the assortment, the manufacturer wants retailer 1 to carry both the SB and the NB. Thus, to achieve this, manufacturer $M$ attempts to set a lower NB wholesale price. Then, retailer 1 accepts full-line assortment, resulting in the equilibrium. This effect of lowering the NB wholesale price dominates the effect of enjoying a higher price under the AMR scenario with a single product, which implies that the MAR scenario with assortment $F$ is the most profitable scenario.

\section{Manufacturer's Profit and Social Welfare}

In this section, we analyze the impact on the manufacturer's profit and social welfare under the optimal strategy for the SB retailer shown in the previous section. Specifically, we evaluate manufacturer M's profit in the equilibrium in Section 5.1 and social welfare in the equilibrium in Section 5.2. As a result of our analysis, we finally obtain Proposition 5.
5.1. Manufacturer's Profit. We now derive manufacturer M's profit in the subgame perfect equilibrium, $\pi_{M}^{*}$. As shown in the propositions in the previous section, retailer l's optimal strategy is divided into three according to the degree of substitutability between the NB and the SB. Therefore, $\pi_{M}^{*}$ also consists of three parts as follows:

$$
\begin{aligned}
& \pi_{M}^{*} \\
& = \begin{cases}\frac{3}{16} & 0<\beta<\bar{\beta} \\
\left(\left(9-3 \beta^{2}\right)\right. & (\text { ARM with } F), \\
\times \sqrt{\beta(\beta+1)\left(\beta^{4}-\beta^{3}-2 \beta^{2}-2 \beta+6\right)} & \\
\left.-6 \beta\left(\beta^{4}-\beta^{3}-2 \beta^{2}-2 \beta+6\right)\right) & \\
\times\left(2(\beta+1)\left(3-\beta^{2}\right)^{2}\right)^{-1} & \bar{\beta}<\beta<\widehat{\beta} \\
\frac{1}{6} & \text { (MAR with } F), \\
& \hat{\beta}<\beta<1 \\
& \text { (AMR with } S) .\end{cases}
\end{aligned}
$$

The manufacturer's equilibrium profit decreases but not monotonically in $\beta$. For $0<\beta<\widetilde{\beta}$ and $\widehat{\beta}<\beta<1$, the profit is constant. This is because under ARM and AMR, retailer 1 always sets the $\mathrm{SB}$ wholesale price at the minimum value for which manufacturer $M$ accepts SB production. Therefore, it follows that, at this price, the manufacturer's profit must be equivalent to the profit when it carries only the $\mathrm{NB}$, which is clearly constant in $\beta$. On the other hand, $\pi_{M}$ is strictly decreasing in $\beta$ for $\bar{\beta}<\beta<\widehat{\beta}$. In this case, retailer 1's optimal strategy is MAR. As explained in Section 4.3, under MAR, the manufacturer lowers the NB wholesale price so that retailer 1 is better off choosing full-line assortment. Therefore, the equilibrium NB wholesale price and the resulting profit are decreasing in $\beta$, since a higher $\beta$ implies intense competition.

We now consider the situation in which only the NB exists as a benchmark. The specific game under this situation is formulated as follows.

Game with only the NB. Given the inverse demand function $P_{n}=1-\left(q_{1}+q_{2}+q_{3}\right)$,

(a) manufacturer $M$ sets the NB wholesale price, $w_{n}$;

(b) retailers 1, 2, and 3 simultaneously choose their quantities of NB, $q_{1}, q_{2}$, and $q_{3}$, respectively.

The precise description of the equilibrium outcome of this game is provided in the Appendix. The profit of manufacturer $M$ in the equilibrium is $3 / 16$. Therefore, as compared to this value, manufacturer $M$ 's profit in the optimal strategy of our original game is lower for $\bar{\beta}<\beta<1$. That is, it follows that if the differentiation between the SB and the NB is sufficiently high, introduction of an SB by a dominant retailer does not change manufacturer $M$ 's profit; otherwise, introduction of an SB decreases it. 
5.2. Social Welfare. We now evaluate the equilibrium outcome of our game in terms of social welfare. To do this, we compare social welfare in the equilibrium under all possible scenarios and assortments in our framework. Specifically, given an assortment $x \in F, S$ and a scenario $y \in \mathrm{ARM}, \mathrm{AMR}$, MAR, let $q_{i}^{y(x)}$ be the total quantity of product $i(i=n, s)$ in the equilibrium. It should be noted that because the three retailers are homogeneous with regard to offering the NB, the consumer surplus for the NB can be expressed as a function of the total quantity $q_{n}^{y(x)}=q_{1}^{y(x)}+q_{2}^{y(x)}+q_{3}^{y(x)}$. Since the value of social welfare SW is given as the sum of consumer surplus (CS) and the profits of manufacturer $M$ and of the three retailers, it is specifically described as follows:

$$
\begin{aligned}
S W^{y(x)}= & C S^{y(x)}+\pi_{M}^{y(x)}+\sum_{i=1,2,3} \pi_{i}^{y(x)} \\
= & u\left(q_{n}^{y(x)}, q_{s}^{y(x)}\right)-\sum_{j=n, s} p_{j}^{y(x)} q_{j}^{y(x)} \\
& +\sum_{j=n, s}\left\{w_{j}^{y(x)} q_{j}^{y(x)}+\left(p_{j}^{y(x)} q_{j}^{y(x)}-w_{j}^{y(x)} q_{j}^{y(x)}\right)\right\} \\
= & u\left(q_{n}^{y(x)}, q_{s}^{y(x)}\right) \\
= & -\frac{1}{2}\left(\left(q_{n}^{y(x)}\right)^{2}+2 \beta q_{n}^{y(x)} q_{s}^{y(x)}+\left(q_{s}^{y(x)}\right)^{2}\right) \\
& +q_{n}^{y(x)}+q_{s}^{y(x)},
\end{aligned}
$$

where $w_{j}^{y(x)}$ and $p_{j}^{y(x)}$ are the equilibrium wholesale price and retail price of product $j$ under scenario $y$ with assortment $x$, respectively. We note that the last equality is derived from the quadratic utility function of a representative consumer for a linear demand function (see Vives [43] for details). Therefore, it follows that social welfare reduces to only the utility's welfare. In addition, we also note that the utility is monotonically increasing in the quantity in the region where $p_{s}=1-q_{s}-\beta\left(q_{1}+q_{2}+q_{3}\right)>0$ and $p_{n}=1-\beta q_{s}-\left(q_{1}+q_{2}+q_{3}\right)>$ 0 (see Vives [43] for details). Then, we immediately obtain the following proposition.

Proposition 5. Suppose that given any scenario, all players compete in determining their wholesale prices and/or setting sales quantities. Then, there necessarily exists some $\beta^{\prime \prime}(0<$ $\left.\beta^{\prime \prime}<1\right)$ such that

(1) if $0<\beta<\beta^{\prime \prime}$, then the ARM scenario with assortment $F$ is the most socially efficient scenario;

(2) if $\beta^{\prime \prime}<\beta<1$, then the MAR scenario with assortment $F$ is the most socially efficient scenario.

Proposition 5 shows that if the SB and the NB are highly or moderately differentiated, the optimal scenario for retailer 1 just coincides with the scenario that maximizes the social welfare. Otherwise, the SB retailer's optimal strategy is not socially desirable. If the two products are differentiated, it is always desirable for consumers that both products are supplied with lower prices. As explained earlier, if both are well differentiated $(0<\beta<\widehat{\beta})$, this can be realized in the equilibrium with $\operatorname{ARM}(0<\beta<\bar{\beta})$ or $\operatorname{MAR}(\bar{\beta}<\beta<$ $\widehat{\beta})$. However, as both products are less differentiated, retailer 1 cannot benefit from full-line assortment due to severe cannibalization, which results in it taking the single-product strategy (AMR with $S$ ) in the equilibrium. Unfortunately, this is not beneficial for consumers as a whole. More precisely, although the SB consumers benefit from the single-product strategy, the decline in the NB consumers' utility exceeds this positive effect. In fact, for any $\beta(0<\beta<1)$, we have

$$
\begin{aligned}
q_{s}^{\operatorname{ARM}(F)} & =\frac{\sqrt{3\left(\beta^{4}-4 \beta^{2}+3\right)}-\beta^{2}+3}{4(\beta+1)\left(3-\beta^{2}\right)}<\frac{1}{2(\beta+1)} \\
& =q_{s}^{\mathrm{MAR}(F)}<\frac{3-2 \beta}{2\left(3-\beta^{2}\right)}=q_{s}^{\operatorname{AMR}(S)} .
\end{aligned}
$$

However, for the NB, we have

$$
\begin{aligned}
& q_{n}^{\operatorname{AMR}(S)} \\
& \quad=\frac{3+\beta^{2}-3 \beta}{3\left(3-\beta^{2}\right)} \\
& \quad<\max \left\{\frac{\beta+3}{8(\beta+1)},\right. \\
& \quad=\max \left\{q_{n}^{\operatorname{ARM}(F)}, q_{n}^{\operatorname{MAR}(F)}\right\},
\end{aligned}
$$

which implies that the NB quantity under AMR with a single product is always lower than that under the strategy maximizing social welfare. This is because under AMR with a single product, retailer 1 does not carry the $\mathrm{NB}$, and furthermore, retailers 2 and 3 reduce their NB quantities to secure marginal profits in response to a higher wholesale price set by the manufacturer.

\section{Conclusion}

Using a game-theoretic approach, this paper analyzed the optimal strategy of a dominant retailer focusing on assortment, the timing of the assortment decision, and the timing of outsourcing (that of offering the SB wholesale price), all under the assumption that the retailer outsources the production of its SB to an NB manufacturer. As a result, we obtained the following implications.

First, the optimal strategy for the SB retailer is classified depending on the degree of differentiation between the SB and the NB. If both products are sufficiently differentiated, a retailer can benefit the most by carrying both the $S B$ and the NB and offer the SB wholesale price as the first-mover 
before the NB manufacturer sets its wholesale price. However, as both products are less differentiated, both the SB retailer and the manufacturer suffer from cannibalization between the two products, and, thus, in order to avoid the rejection of SB production, the retailer benefits from offering only the SB. In this case, the retailer should offer its wholesale price after the manufacturer sets the NB wholesale price in order to maintain a higher retail price. Nevertheless, for a moderately differentiated case, if the SB retailer determines its assortment after the manufacturer sets the NB wholesale price, then full-line assortment becomes optimal since the manufacturer lowers the NB wholesale price in this case.

We also obtained some implications of our equilibrium results in terms of manufacturer's profit and social welfare. As compared to the situation where only the $\mathrm{NB}$ is in the market, the manufacturer's profit decreases if the SB and the NB are not sufficiently differentiated. This is because, in this case, the quantity of the NB excessively decreases as a whole, that is, not only the SB retailer does not carry the NB but also the other retailers reduce their NB quantities to secure marginal profits in response to a higher wholesale price set by the manufacturer. Therefore, this also decreases consumer utility, and, thus, the equilibrium is socially inefficient. In contrast, if both products are sufficiently differentiated, the optimal strategy of the retailer is socially desirable.

In a normative sense, rather than in a positive sense, these results can give new managerial insights into a retailer's strategy of producing its SB. If it attempts to outsource $\mathrm{SB}$ production to an $\mathrm{NB}$ manufacturer, it should carefully consider the strategic interaction between the two products. In particular, this sensitively depends on the degree of substitutability between the SB and the NB, and, thus, the retailer should take this into account in deciding its outsourcing strategy. However, if both products are highly horizontally differentiated, full-line assortment is not only beneficial for the SB retailer but also socially desirable. We suggest that dominant retailers in the real-world should be encouraged to produce SBs that are well horizontally differentiated from NBs, as 7-Eleven aggressively introduces such SBs in Japan.

In this study, as in much of the economic literature and as frequently utilized in operations research literature, we developed a highly stylized model to be analytically tractable. Because of this simplicity, our results might not directly contribute to practitioners' decision making at the operational level. However, we are sure that our findings provide a conceptual benchmark and offer rich managerial insights, which would help in the decision-making process at the strategic level. In particular, as seen above, our approach succeeds in obtaining the strategic logic underlying our results. By understanding this logic precisely, one might be able to obtain intuitions for strategies under other realistic situations.

Finally, we mention the limitations of our study. This study considered the case where the manufacturer is a monopoly. It would be interesting to consider cases of competitive manufacturers. In particular, it would be meaningful to investigate the situation in which a retailer can choose the manufacturer to which it outsources SB production. In addition, we have not considered an only-symmetric cost structure, which is left open for the possibility of further investigation. For example, it might be interesting to investigate how additional costs associated with a wider product assortment change our results. Further, at least in practice, other costs such as holding cost, promotion cost, and opportunity cost should be incurred, which can be asymmetric between SBs and NBs. Moreover, a strategic interaction between retailers and manufacturers might change such a cost structure. For example, with economies of scale, manufacturers might be able to reduce their NB production costs by accepting SB production. By incorporating these factors into models, we would be able to provide richer insights into SB strategy. However, unfortunately, it seems that the analysis presented in this paper cannot be directly applied to these tasks; this is a challenge for the future.

\section{Appendix}

This Appendix is divided into two parts. Appendix A gives precise descriptions of our equilibrium outcomes. Appendix B gives proofs for the results of our propositions. However, as mentioned later, many parts of proofs are straightforward through direct calculations. So, we here omit the details in order to avoid tedious discussion, although they can be obtained from the authors upon request.

\section{A. Equilibrium Outcomes}

We first present tables which summarize the equilibrium outcomes under each scenario as well as the case where only the NB exists in the market. We then explain the outline of deriving them. We note that some of outcomes are given as approximate values.

\section{Equilibrium Outcomes. See Tables 5-10.}

The Derivation of the Equilibrium. For each scenario, we can directly derive the equilibrium by using a backward induction. However, it would be a lengthy process to give details of these calculations. So, we here show the detail only for the ARM scenario under the assortment $F$ as an example.

We first consider retailers' decision in Stage 5, given the decisions in the previous stages. Provided that the manufacturer $M$ accepts the SB production in Stage 3, three retailers simultaneously solve the following profit-maximizing problems:

$$
\begin{aligned}
\max _{q_{s}, q_{1}} \pi_{1}= & \left(p_{s}-w_{s}\right) q_{s}+\left(p_{n}-w_{n}\right) q_{1} \\
= & \left(1-q_{s}-\beta\left(q_{1}+q_{2}+q_{3}\right)-w_{s}\right) q_{s} \\
& +\left(1-\beta q_{s}-q_{1}-q_{2}-q_{3}-w_{n}\right) q_{1} \\
\max _{q_{2}} \pi_{2}= & \left(p_{n}-w_{n}\right) q_{2} \\
= & \left(1-\beta q_{s}-q_{1}-q_{2}-q_{3}-w_{n}\right) q_{2}
\end{aligned}
$$


TABLE 5: Equilibrium outcome under ARM scenario with assortment F.

\begin{tabular}{|c|c|c|}
\hline & For $\beta<\widetilde{\beta}$ & For $\beta \geq \widetilde{\beta}$ \\
\hline \multirow[b]{2}{*}{$p_{n}$} & $-2 \sqrt{3} \beta \sqrt{\beta^{4}-4 \beta^{2}+3}-5 \beta^{3}-5 \beta^{2}+15 \beta+15$ & $13 \beta+7$ \\
\hline & $8 \frac{8(\beta+1)\left(3-\beta^{2}\right)}{1}$ & $\overline{16(\beta+1)}$ \\
\hline \multirow[b]{2}{*}{$p_{s}$} & $-2 \sqrt{3} \sqrt{\beta^{4}-4 \beta^{2}+3}+\beta^{4}-5 \beta^{3}-9 \beta^{2}+15 \beta+18$ & $-2 \beta^{3}+10 \beta^{2}+15 \beta-3$ \\
\hline & $\overline{8(\beta+1)}\left(3-\beta^{2}\right)$ & $16 \beta(\beta+1)$ \\
\hline \multirow[b]{2}{*}{$w_{n}$} & $-2 \sqrt{3} \beta \sqrt{\beta^{4}-4 \beta^{2}+3}-3 \beta^{3}-3 \beta^{2}+9 \beta+9$ & $3 \beta+1$ \\
\hline & $6(\beta+1)\left(3-\beta^{2}\right)$ & $\overline{4(\beta+1)}$ \\
\hline \multirow[b]{2}{*}{$w_{s}$} & $-\sqrt{3} \sqrt{\beta^{4}-4 \beta^{2}+3}+3 \beta+3$ & $-\beta^{3}+5 \beta^{2}+7 \beta-3$ \\
\hline & $\overline{6 \beta+6}$ & $8 \beta^{2}+8 \beta$ \\
\hline \multirow[b]{2}{*}{$m_{n}$} & $2 \sqrt{3} \beta \sqrt{\beta^{4}-4 \beta^{2}+3}-3 \beta^{3}-3 \beta^{2}+9 \beta+9$ & $\beta+3$ \\
\hline & $\overline{24(\beta+1)\left(3-\beta^{2}\right)}$ & $\overline{16(\beta+1)}$ \\
\hline \multirow[b]{2}{*}{$m_{s}$} & $3 \beta^{4}-3 \beta^{3}-\sqrt{1-\beta} \sqrt{\beta+1} \sqrt{3-\beta^{2}}\left(4 \sqrt{3} \beta^{2}-6 \sqrt{3}\right)-15 \beta^{2}+9 \beta+18$ & $\beta+3$ \\
\hline & $24(\beta+1)\left(3-\beta^{2}\right)$ & $\overline{16 \beta(\beta+1)}$ \\
\hline \multirow[b]{2}{*}{$q_{s}$} & $\sqrt{3} \sqrt{\beta^{4}-4 \beta^{2}+3}-\beta^{2}+3$ & $\beta+3$ \\
\hline & $\frac{4(\beta+1)\left(3-\beta^{2}\right)}{1}$ & $\overline{16 \beta(\beta+1)}$ \\
\hline \multirow[b]{2}{*}{$q_{1}$} & $-4 \sqrt{3} \beta \sqrt{\beta^{4}-4 \beta^{2}+3}+3 \beta^{3}-3 \beta^{2}-9 \beta+9$ & \\
\hline & $\overline{24(\beta+1)\left(3-\beta^{2}\right)}$ & 0 \\
\hline \multirow{2}{*}{$q_{2}\left(=q_{3}\right)$} & $2 \sqrt{3} \beta \sqrt{\beta^{4}-4 \beta^{2}+3-3 \beta^{3}-3 \beta^{2}+9 \beta+9}$ & $\beta+3$ \\
\hline & $\frac{24(\beta+1)\left(3-\beta^{2}\right)}{1}$ & $\overline{16(\beta+1)}$ \\
\hline \multirow[b]{2}{*}{$\pi_{1}$} & $4 \sqrt{3} \sqrt{(1-\beta)(1+\beta)\left(3-\beta^{2}\right)}(6-5 \beta)+41 \beta^{3}-47 \beta^{2}-63 \beta+81$ & $(\beta+3)^{2}$ \\
\hline & $\overline{192(\beta+1)\left(3-\beta^{2}\right)}$ & $\overline{256 \beta^{2}(\beta+1)^{2}}$ \\
\hline \multirow[b]{2}{*}{$\pi_{M}$} & $\underline{3}$ & $\underline{(\beta+3)\left(11 \beta^{3}+9 \beta^{2}+7 \beta-3\right)}$ \\
\hline & $\overline{16}$ & $128 \beta^{2}(\beta+1)^{2}$ \\
\hline
\end{tabular}

Where $\widetilde{\beta} \approx 0.448$ is the unique feasible solution for $13 \beta^{3}+19 \beta^{2}+9 \beta-9=0$.

$$
\begin{aligned}
\max _{q_{3}} \pi_{3} & =\left(p_{n}-w_{n}\right) q_{3} \\
& =\left(1-\beta q_{s}-q_{1}-q_{2}-q_{3}-w_{n}\right) q_{3}
\end{aligned}
$$

The equilibrium in this subgame is uniquely given as the interior solution as follows:

$$
\begin{gathered}
q_{s}=\frac{1-w_{s}+\beta w_{n}-\beta}{2(1-\beta)(\beta+1)}, \\
q_{1}=\frac{2 \beta w_{s}-\beta^{2} w_{n}-w_{n}+\beta^{2}-2 \beta+1}{4(1-\beta)(\beta+1)}, \\
q_{2}=q_{3}=\frac{1-w_{n}}{4} .
\end{gathered}
$$

Therefore, in Stage 4, the manufacturer $M$ solves the following optimization problem with respect to the NB wholesales price, given the SB wholesales price. Consider

$$
\begin{aligned}
\max _{w_{n}} \pi_{M}= & \left(\left(\beta^{2}-3\right) w_{n}^{2}+\left(4 \beta w_{s}-\beta^{2}-2 \beta+3\right) w_{n}\right. \\
& \left.-2 w_{s}^{2}+(-2 \beta+2) w_{s}\right) \\
& \times\left(4-4 \beta^{2}\right)^{-1} .
\end{aligned}
$$

The optimal $w_{n}$ is given as the interior solution as

$$
w_{n}=\frac{4 \beta w_{s}-\beta^{2}-2 \beta+3}{6-2 \beta^{2}} .
$$

As a result, it can expect to obtain the following profit:

$$
\begin{aligned}
& \pi_{M} \\
& =\frac{9-24 \beta w_{s}^{2}-24 w_{s}^{2}+24 \beta w_{s}+24 w_{s}-\beta^{3}-5 \beta^{2}-3 \beta}{16(\beta+1)\left(3-\beta^{2}\right)} .
\end{aligned}
$$

On the other hand, if $M$ rejects the SB production, then it can benefit from only the NB. In this case, as seen from Table 10, the equilibrium profit of the manufacturer $M$ is $3 / 16$. Consequently, in Stage 3, $M$ accepts the SB production when the profit (A.5) exceeds $3 / 16$, which derives the following inequality with respect to $w_{s}$ :

$$
\begin{gathered}
-\frac{\sqrt{3} \sqrt{\beta^{4}-4 \beta^{2}+3}-3 \beta-3}{6 \beta+6} \\
<w_{s}<\frac{\sqrt{3} \sqrt{\beta^{4}-4 \beta^{2}+3}+3 \beta+3}{6 \beta+6} .
\end{gathered}
$$


TABLE 6: Equilibrium outcome under ARM scenario with assortment S.

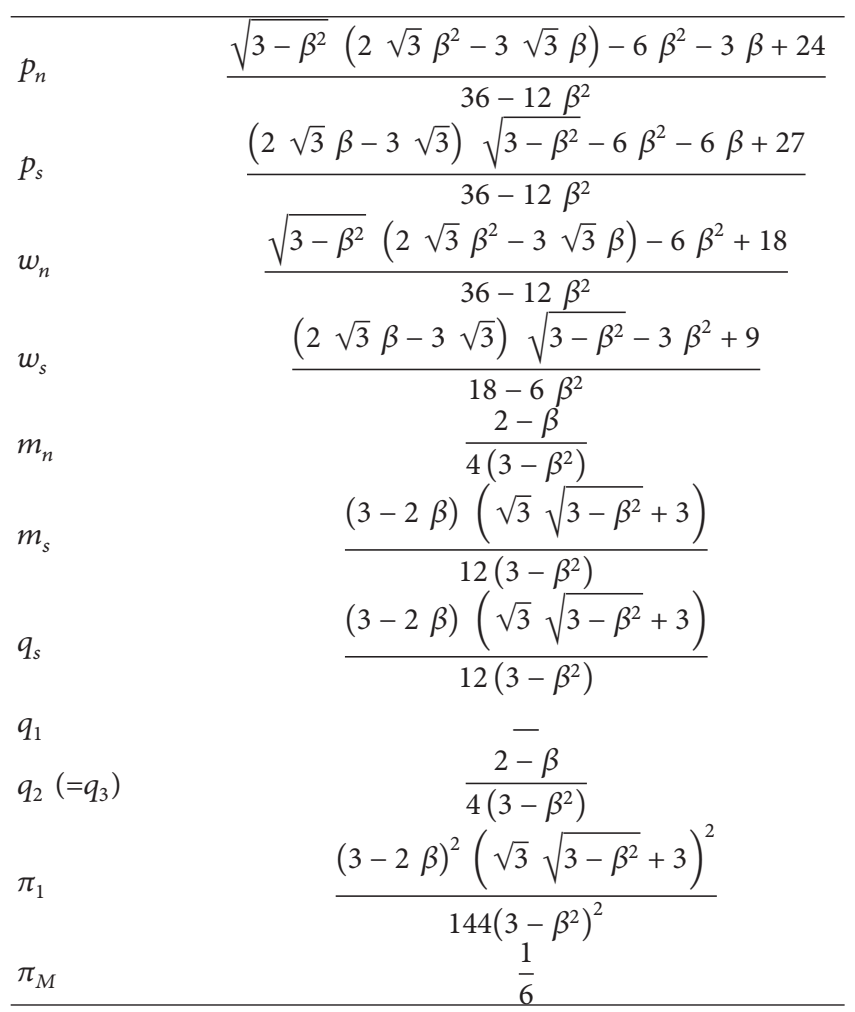

TABLE 7: Equilibrium outcome under AMR scenario with assortment F.

\begin{tabular}{lcc}
\hline & For $\beta<1 / 7$ & For $\beta \geq 1 / 7$ \\
\hline$p_{n}$ & $\frac{5}{8}$ & $\frac{14 \beta^{2}-3 \beta+4}{4\left(5 \beta^{2}+1\right)}$ \\
$p_{s}$ & $\frac{\beta+4}{8}$ & $\frac{-4 \beta^{3}+18 \beta^{2}-2 \beta+3}{4\left(5 \beta^{2}+1\right)}$ \\
$w_{n}$ & $\frac{1}{2}$ & $\frac{1+3 \beta^{2}-\beta}{5 \beta^{2}+1}$ \\
$w_{s}$ & $\frac{\beta}{2}$ & $\frac{-2 \beta^{3}+9 \beta^{2}-2 \beta+1}{2\left(5 \beta^{2}+1\right)}$ \\
$m_{n}$ & $\frac{1}{2}$ & $\frac{\beta(2 \beta+1)}{4\left(5 \beta^{2}+1\right)}$ \\
$m_{s}$ & $\frac{4-3 \beta}{8}$ & $\frac{2 \beta+1}{4\left(5 \beta^{2}+1\right)}$ \\
$q_{s}$ & $\frac{1}{2(\beta+1)}$ & $\frac{2 \beta^{3}-\beta^{2}+2 \beta}{4(1-\beta)(\beta+1)\left(5 \beta^{2}+1\right)}$ \\
$q_{1}$ & $\frac{1-3 \beta}{8(\beta+1)}$ & $\frac{\beta(2 \beta+1)}{4\left(5 \beta^{2}+1\right)}$ \\
$q_{2}\left(=q_{3}\right)$ & $\frac{1}{8}$ & $\frac{(2 \beta+1)^{2}}{16\left(5 \beta^{2}+1\right)^{2}}$ \\
$\pi_{1}$ & $\frac{17-15 \beta}{64(\beta+1)}$ & $\frac{(2 \beta+1)^{2}}{8\left(5 \beta^{2}+1\right)}$ \\
\hline
\end{tabular}

TABLE 8: Equilibrium outcome under AMR scenario with assortment $\mathrm{S}$.

\begin{tabular}{lc}
\hline$p_{n}$ & $\frac{12-2 \beta^{2}-3 \beta}{6\left(3-\beta^{2}\right)}$ \\
$p_{s}$ & $\frac{9-2 \beta^{3}}{6\left(3-\beta^{2}\right)}$ \\
$w_{n}$ & $\frac{1}{2}$ \\
$w_{s}$ & $\frac{\beta}{3}$ \\
$m_{n}$ & $\frac{\beta^{2}-3 \beta+3}{6\left(3-\beta^{2}\right)}$ \\
$m_{s}$ & $\frac{3-2 \beta}{2\left(3-\beta^{2}\right)}$ \\
$q_{s}$ & $\frac{3-2 \beta}{2\left(3-\beta^{2}\right)}$ \\
$q_{1}$ & $\frac{\beta^{2}-3 \beta+3}{6\left(3-\beta^{2}\right)}$ \\
$q_{2}\left(=q_{3}\right)$ & $\frac{(3-2 \beta)^{2}}{4\left(3-\beta^{2}\right)^{2}}$ \\
$\pi_{1}$ & $\frac{1}{6}$ \\
$\pi_{M}$ &
\end{tabular}

In addition, from what is mentioned above, we must have that $q_{1}$ and $q_{s}$ are positive in the equilibrium, which implies that

$$
-\frac{\beta^{3}-5 \beta^{2}-7 \beta+3}{8 \beta^{2}+8 \beta}<w_{s}<\frac{6-\beta^{2}+3 \beta}{6 \beta+6} .
$$

Therefore, given $\epsilon$ as a sufficiently small number, it follows that $\pi_{M}$ is maximized at $w_{s}=\left(\left(-\sqrt{3} \sqrt{\beta^{4}-4 \beta^{2}+3}+3 \beta+\right.\right.$ $3) /(6 \beta+6))+\epsilon$, for $0<\beta<\widetilde{\beta}$, and $w_{s}=\left(\left(-\beta^{3}+5 \beta^{2}+7 \beta-\right.\right.$ $\left.3) /\left(8 \beta^{2}+8 \beta\right)\right)+\epsilon$, for $\tilde{\beta}<\beta<1$, where $\tilde{\beta}$ is the unique feasible solution for $\left(\left(-\sqrt{3} \sqrt{\beta^{4}-4 \beta^{2}+3}+3 \beta+3\right) /(6 \beta+6)\right)=\left(\left(-\beta^{3}+\right.\right.$ $\left.\left.5 \beta^{2}+7 \beta-3\right) /\left(8 \beta^{2}+8 \beta\right)\right)$; that is, $13 \beta^{3}+19 \beta^{2}+9 \beta-9=0$. For each case, by substituting this $w_{s}$ into equations with respect to other variables determined in the subsequent stages and taking $\epsilon \rightarrow 0$, the results follow.

\section{B. Proofs of Propositions}

We next give the proofs of our propositions. For notational convenience, we denote the equilibrium profit of retailer 1 under assortment $x \in F, S$ and scenario $y \in$ ARM, AMR, MAR by $\pi_{1}^{y(x)}$.

Proof of Proposition 1. We compare $\pi_{1}^{\operatorname{ARM}(F)}$ and $\pi_{1}^{\operatorname{AMR}(F)}$, which can be seen in Tables 5 and 7 , respectively. Since $1 / 7<$ $\widetilde{\beta}$, it is sufficient to calculate $\pi_{1}^{\operatorname{ARM}(F)}-\pi_{1}^{\operatorname{AMR}(F)}$ for three cases of $0<\beta<1 / 7,1 / 7<\beta<\tilde{\beta}$, and $\widetilde{\beta}<\beta<1$. Although the calculation is rather complicated, we can directly derive $\pi_{1}^{\operatorname{ARM}(F)}>\pi_{1}^{\operatorname{AMR}(F)}$ for each case. 
TABLE 9: Equilibrium outcome under MAR scenario.

\begin{tabular}{|c|c|c|c|}
\hline & For $0<\beta<\beta_{1}$ & For $\beta_{1}<\beta<\widehat{\beta}$ & For $\widehat{\beta}<\beta<1$ \\
\hline \multirow[b]{2}{*}{$p_{n}$} & 5 & $6+6 \beta-2 \beta^{2}-2 \beta^{3}-3 \sqrt{\beta\left(6+4 \beta-4 \beta^{2}-3 \beta^{3}+\beta^{5}\right)}$ & $12-2 \beta^{2}-3 \beta$ \\
\hline & $\overline{8}$ & $2(1+\beta)\left(3-\beta^{2}\right)$ & $\frac{6\left(3-\beta^{2}\right)}{}$ \\
\hline \multirow{2}{*}{$p_{s}$} & $\beta+4$ & $3+2 \beta^{2}-2 \beta^{3}-\beta^{4}+3 \beta\left(2-\sqrt{\beta\left(6+4 \beta-4 \beta^{2}-3 \beta^{3}+\beta^{5}\right)}\right)$ & $9-2 \beta^{3}$ \\
\hline & $\overline{8}$ & $2(1+\beta)\left(3-\beta^{2}\right)$ & $\overline{6\left(3-\beta^{2}\right)}$ \\
\hline \multirow{2}{*}{$w_{n}$} & 1 & $(1+\beta)\left(3-\beta^{2}\right)-2 \sqrt{\beta\left(6+4 \beta-4 \beta^{2}-3 \beta^{3}+\beta^{5}\right)}$ & - $5=$ \\
\hline & $\overline{2}$ & $(1+\beta)\left(3-\beta^{2}\right)$ & $\overline{2}$ \\
\hline \multirow{2}{*}{$w_{s}$} & $\beta$ & $\beta\left((1+\beta)\left(3-\beta^{2}\right)-2 \sqrt{\beta\left(6+4 \beta-4 \beta^{2}-3 \beta^{3}+\beta^{5}\right)}\right)$ & $\beta$ \\
\hline & $\overline{2}$ & $\frac{(1+\beta)\left(3-\beta^{2}\right)}{1}$ & $\overline{3}$ \\
\hline \multirow{2}{*}{$m_{n}$} & 1 & $\sqrt{\beta\left(6+4 \beta-4 \beta^{2}-3 \beta^{3}+\beta^{5}\right)}$ & $\beta^{2}-3 \beta+3$ \\
\hline & $\overline{2}$ & $2(1+\beta)\left(3-\beta^{2}\right)$ & $\overline{6\left(3-\beta^{2}\right)}$ \\
\hline \multirow{2}{*}{$m_{s}$} & $4-3 \beta$ & $3-4 \beta^{2}+\beta^{4}+\beta \sqrt{\beta\left(6+4 \beta-4 \beta^{2}-3 \beta^{3}+\beta^{5}\right)}$ & $3-2 \beta$ \\
\hline & $\begin{array}{l}8 \\
1\end{array}$ & $\begin{array}{c}2(1+\beta)\left(3-\beta^{2}\right) \\
1\end{array}$ & $\begin{array}{l}\overline{2\left(3-\beta^{2}\right)} \\
3-2 \beta\end{array}$ \\
\hline$q_{s}$ & $\overline{2(\beta+1)}$ & $\overline{2(1+\beta)}$ & $\overline{2\left(3-\beta^{2}\right)}$ \\
\hline \multirow[b]{2}{*}{$q_{1}$} & $1-3 \beta$ & $\beta^{3}-3 \beta+\sqrt{\beta\left(6+4 \beta-4 \beta^{2}-3 \beta^{3}+\beta^{5}\right)}$ & - \\
\hline & $\overline{8(\beta+1)}$ & $\frac{2(1+\beta)\left(3-\beta^{2}\right)}{2}$ & - \\
\hline \multirow{2}{*}{$q_{2}\left(=q_{3}\right)$} & 1 & $\sqrt{\beta\left(6+4 \beta-4 \beta^{2}-3 \beta^{3}+\beta^{5}\right)}$ & $\beta^{2}-3 \beta+3$ \\
\hline & $\overline{8}$ & $2(1+\beta)\left(3-\beta^{2}\right)$ & $6\left(3-\beta^{2}\right)$ \\
\hline \multirow{2}{*}{$\pi_{1}$} & $\underline{17-15 \beta}$ & $\underline{(3-2 \beta)^{2}}$ & $(3-2 \beta)^{2}$ \\
\hline & $\overline{64(\beta+1)}$ & $\overline{4\left(3-\beta^{2}\right)^{2}}$ & $4\left(3-\beta^{2}\right)^{2}$ \\
\hline \multirow[b]{2}{*}{$\pi_{M}$} & 3 & $-36 \beta+12 \beta^{2}+12 \beta^{3}+6 \beta^{4}-6 \beta^{5}+3\left(3-\beta^{2}\right) \sqrt{\beta\left(6+4 \beta-4 \beta^{2}-3 \beta^{3}+\beta^{5}\right)}$ & 1 \\
\hline & $\overline{16}$ & $2(1+\beta)\left(3-\beta^{2}\right)^{2}$ & $\overline{6}$ \\
\hline
\end{tabular}

Where $\beta_{1} \approx 0.107$ is the unique feasible solution for $\pi_{1}^{\mathrm{AMR}(\mathrm{F})}=\pi_{1}^{\mathrm{AMR}(\mathrm{S})}$ in $\beta<1 / 7$ (equivalent to $15 \beta^{5}-17 \beta^{4}-26 \beta^{3}-26 \beta^{2}+87 \beta-9=0$ ) and $\widehat{\beta} \approx 0.215$ is the unique feasible solution for $\pi_{M}^{\operatorname{MAR}(F)}(\beta)=\pi_{M}^{\operatorname{MAR}(S)}(\beta)$ (equivalent to $9+117 \beta-42 \beta^{3}-17 \beta^{4}+19 \beta^{5}-27 \sqrt{\beta\left(6+4 \beta-4 \beta^{2}-3 \beta^{3}+\beta^{5}\right)}+3 \beta^{2}(-14+$ $\left.\left.3 \sqrt{\beta\left(6+4 \beta-4 \beta^{2}-3 \beta^{3}+\beta^{5}\right)}\right)=0\right)$, respectively.

TABLE 10: Equilibrium outcome for the case where only the NB exists in the market.

\begin{tabular}{lc}
\hline$p_{n}$ & $\frac{5}{8}$ \\
$w_{n}$ & $\frac{1}{2}$ \\
$m_{n}$ & $\frac{1}{8}$ \\
$q_{1}$ & $\frac{1}{8}$ \\
$q_{2}\left(=q_{3}\right)$ & $\frac{1}{8}$ \\
$\pi_{1}$ & $\frac{1}{64}$ \\
$\pi_{M}$ & $\frac{3}{16}$ \\
\hline
\end{tabular}

Proof of Proposition 2. From Tables 6 and 8, the proof is reduced to finding the sign of $\left(\left((3-2 \beta)^{2}\left(\sqrt{3} \sqrt{3-\beta^{2}}+3\right)^{2}\right) /\right.$ $\left.\left(144\left(3-\beta^{2}\right)^{2}\right)\right)-\left((3-2 \beta)^{2} / 4\left(3-\beta^{2}\right)^{2}\right)$. Through simple yet tedious algebra, it can be verified that this value is negative for any feasible $\beta$, which completes the proof.
Proof of Proposition 3. We compare $\pi_{1}^{\operatorname{ARM}(F)}$ and $\pi_{1}^{\operatorname{AMR}(S)}$, which can be seen in Tables 5 and 8 , respectively. We first consider the case of $0<\beta<\widetilde{\beta}$ and define the value of $\pi_{1}^{\operatorname{ARM}(F)}-\pi_{1}^{\operatorname{AMR}(S)}$ at $\beta(0<\beta<\widetilde{\beta})$ as $\Delta \pi_{1}(\beta)$. Then, through simple yet tedious algebra, we can show that $\Delta \pi_{1}$ is continuously decreasing in $\beta$ in $0<\beta<1 / 2, \Delta \pi_{1}(0)>0$, and $\Delta \pi_{1}(2 / 5)<0$, which implies that $\Delta \pi_{1}$ has the unique solution $\beta^{*}$ for equation $\Delta \pi_{1}(\beta)=0$ in $0<\beta<2 / 5$. Since we have $2 / 5<\widetilde{\beta}<1 / 2$, it follows that $\Delta \pi_{1}$ is positive in $0<\beta<\beta^{*}$, while negative in $\beta^{*}<\beta<\widetilde{\beta}$. On the other hand, through some algebra, it can be verified that $\pi_{1}^{\operatorname{ARM}(F)}<\pi_{1}^{\operatorname{AMR}(S)}$ holds for any $\beta$ such that $\widetilde{\beta}<\beta<1$. By summing up these results, we obtain the proposition.

Proof of Proposition 4. By comparing Table 9 with Tables 7 and 8 , we can have that the equilibrium profit under the MAR scenario is equivalent to $\pi_{1}^{\operatorname{AMR}(F)}$ in $0<\beta<\beta_{1}$ and $\pi_{1}^{\operatorname{AMR}(S)}$ in $\widehat{\beta}<\beta<1$, respectively. However, since Proposition 1 ensures that $\pi_{1}^{\operatorname{AMR}(F)}<\pi_{1}^{\operatorname{ARM}(F)}$ holds, the MAR scenario cannot be the most profitable in $0<\beta<\beta_{1}$. On the other hand, we note that, in $\beta_{1}<\beta<\widehat{\beta}$, the value of the equilibrium profit in Table 9 , denoted by $\pi_{1}^{\operatorname{MAR}(F)}$, is 
the approximate one, which is slightly higher than $\pi_{1}^{\mathrm{AMR}(S)}$ (note that as shown in Appendix A, $\widehat{\beta}$ is given as $\beta$ which satisfies $\pi_{M}^{\operatorname{MAR}(F)}(\beta)=\pi_{M}^{\operatorname{MAR}(S)}(\beta)$, where $\pi_{M}^{\operatorname{MAR}(F)}$ and $\pi_{M}^{\operatorname{MAR}(S)}$ are the equilibrium profits of the manufacturer under the corresponding scenarios, resp.). Let $\bar{\beta}$ be the unique feasible solution for $\pi_{1}^{\operatorname{MAR}(F)}=\pi_{1}^{\operatorname{ARM}(F)}$ in $\beta_{1}<\beta<1$. Then, from Proposition 3 and by continuity, we must have $\bar{\beta} \approx \beta^{*}$. On the other hand, through some algebra, it follows that $\beta^{*}<\widehat{\beta}<1$ holds. Therefore, this implies that retailer 1 benefits from the MAR scenario only in $\bar{\beta} \approx \beta^{*}<\beta<\widehat{\beta}$. We thus obtain the two statements in the proposition.

Proof of Proposition 5. For each possible assortment $x \in F, S$ and scenario $y \in \mathrm{ARM}, \mathrm{AMR}, \mathrm{MAR}$, we can derive the social welfare at the equilibrium $\mathrm{SW}^{y(x)}$ by directly substituting the equilibrium quantities of the SB and the NB into (4). With regard to these values, we first show that $\operatorname{SW}^{\operatorname{ARM}(F)}>$ $\mathrm{SW}^{\mathrm{AMR}(F)}$ and $\mathrm{SW}^{\mathrm{ARM}(S)}<\mathrm{SW}^{\mathrm{AMR}(S)}$ hold for any possible $\beta$. Next, we show that $\operatorname{SW}^{\operatorname{ARM}(F)}>\operatorname{SW}^{\operatorname{AMR}(S)}$, for $0<\beta<1 / 2$, while $\operatorname{SW}^{\operatorname{MAR}(F)}>\operatorname{SW}^{\operatorname{AMR}(S)}$, for $1 / 2<\beta<1$. This also implies that $S W^{\operatorname{MAR}(S)}$, which is equivalent to $S W^{\operatorname{AMR}(S)}$ from the discussion in Proposition 4, is less than either SW $\mathrm{SAR}^{\mathrm{MA}(F)}$ or SW ${ }^{\mathrm{ARM}(F)}$. Finally, we have that there exists some $\beta^{\prime \prime}(0<$ $\left.\beta^{\prime \prime}<1\right)$ such that $\operatorname{SW}^{\operatorname{ARM}(F)}>\operatorname{SW}^{\operatorname{MAR}(F)}$, for $0<\beta<\beta^{\prime \prime}$, while $\mathrm{SW}^{\operatorname{ARM}(F)}<\mathrm{SW}^{\mathrm{MAR}(F)}$, for $\beta^{\prime \prime}<\beta<1$, which completes the proof.

\section{Conflict of Interests}

The authors declare that there is no conflict of interests regarding the publication of this paper.

\section{Acknowledgments}

The authors thank the Editor, Takashi Matsuhisa, and two anonymous referees for helpful comments. The second author is supported by the Grants-in-Aid for Scientific Research (C) 24510201 of the Ministry of Education, Culture, Sports, Science and Technology of Japan.

\section{References}

[1] B. Sternquist, International Retailing, The Fairchild Books, New York, NY, USA, 2007.

[2] J. Tirole, The Theory of Industrial Organization, The MIT Press, Cambridge, Mass, USA, 1988.

[3] N. Kumar and J.-B. E. M. Steenkamp, Private Label Strategy: How to Meet the Store Brand Challenge, Harvard Business School Press, Cambridge, Mass, USA, 2007.

[4] The Suntory Website, 2007 (Japanese), http://www.suntory.co. jp/news/2007/9781.html.

[5] The Seven \& i Holdings Website, 2009 (Japanese), http://www.7andi.com/news/pdf/2007/20090721_01.pdf.

[6] TheSuntory Website, 2011 (Japanese), http://www.suntory.co.jp/ news/2011/11250.html.
[7] M. Boyle, "Brand killers store brands aren’t for losers anymore," Fortune, 2003.

[8] S. Choi, "Price competition in a channel structure with a common retailer," Marketing Science, vol. 10, no. 4, pp. 271-296, 1991.

[9] S. Choi, "Price competition in a duopoly common retailer channel," Journal of Retailing, vol. 72, no. 2, pp. 117-134, 1996.

[10] N. C. P. Edirisinghe, B. Bichescu, and W. Shi, "Equilibrium analysis of supply chain structures under power imbalance," European Journal of Operational Research, vol. 214, no. 3, pp. 568-578, 2011.

[11] C. H. Wu, C. W. Chen, and C. C. Hsieh, "Competitive pricing decisions in a two-echelon supply chain with horizontal and vertical competition," International Journal of Production Economics, vol. 135, no. 1, pp. 265-274, 2012.

[12] J. Spengler, "Vertical integration and anti-trust policy," Journal of Political Economy, vol. 58, no. 4, pp. 347-352, 1950.

[13] T. McGuire and R. Staelin, "An industry equilibrium analysis of downstream vertical integration," Marketing Science, vol. 2, no. 2, pp. 161-191, 1983.

[14] A. Jeuland and S. Shugan, "Managing channel profits," Marketing Science, vol. 2, no. 3, pp. 239-272, 2008.

[15] E. Lee and R. Staelin, "Vertical strategic interaction: implications for channel pricing strategy," Marketing Science, vol. 16, no. 3, pp. 185-207, 1997.

[16] E. J. Anderson and Y. Bao, "Price competition with integrated and decentralized supply chains," European Journal of Operational Research, vol. 200, no. 1, pp. 227-234, 2010.

[17] S. Karray, "Effectiveness of retail joint promotions under different channel structures," European Journal of Operational Research, vol. 210, no. 3, pp. 745-751, 2011.

[18] K. Matsui, "Strategic upfront marketing channel integration as an entry barrier," European Journal of Operational Research, vol. 220, no. 3, pp. 865-875, 2012.

[19] P. Majumder and A. Srinivasan, "Leader location, cooperation, and coordination in serial supply chains," Production and Operations Management, vol. 15, no. 1, pp. 22-39, 2006.

[20] T. Geylani, A. Dukes, and K. Srinivasan, "Strategic manufacturer response to a dominant retailer," Marketing Science, vol. 26, no. 2, pp. 164-178, 2007.

[21] G. P. Cachon and P. T. Harker, "Competition and outsourcing with scale economies," Management Science, vol. 48, no. 10, pp. 1314-1333, 2002.

[22] D. Atkins and L. Liang, "A note on competitive supply chains with generalised supply costs," European Journal of Operational Research, vol. 207, no. 3, pp. 1316-1320, 2010.

[23] W. S. Lim and S. J. Tan, "Outsourcing suppliers as downstream competitors: biting the hand that feeds," European Journal of Operational Research, vol. 203, no. 2, pp. 360-369, 2010.

[24] Y. Liu and R. K. Tyagi, "The benefits of competitive upward channel decentralization," Management Science, vol. 57, no. 4, pp. 741-751, 2011.

[25] D. Z. Yu, "Product variety and vertical differentiation in a batch production system," International Journal of Production Economics, vol. 138, no. 2, pp. 314-328, 2012.

[26] N. Matsubayashi, Y. Ishii, K. Watanabe, and Y. Yamada, "Fullline or specialization strategy? The negative effect of product variety on product line strategy," European Journal of Operational Research, vol. 196, no. 2, pp. 795-807, 2009. 
[27] C. S. Tang and R. Yin, "The implications of costs, capacity, and competition on product line selection," European Journal of Operational Research, vol. 200, no. 2, pp. 439-450, 2010.

[28] P. Lacourbe, "A model of product line design and introduction sequence with reservation utility," European Journal of Operational Research, vol. 220, no. 2, pp. 338-348, 2012.

[29] A. Dukes, T. Geylani, and K. Srinivasan, "Strategic assortment reduction by a dominant retailer," Marketing Science, vol. 28, no. 2, pp. 309-319, 2009.

[30] N. Amrouche and G. Zaccour, "Shelf-space allocation of national and private brands," European Journal of Operational Research, vol. 180, no. 2, pp. 648-663, 2007.

[31] M. Kurtulus and L. Toktay, "Category captainship vs. retailer category management under limited retail shelf space," Production and Operations Management, vol. 20, no. 1, pp. 47-56, 2011.

[32] J. A. Quelch and D. Harding, "Brands versus private labels: fighting to win," Harvard Business Review, vol. 74, pp. 99-109, 1996.

[33] R. Batra and I. Sinha, "Consumer-level factors moderating the success of private label brands," Journal of Retailing, vol. 76, no. 2, pp. 175-191, 2000.

[34] D. E. Mills, "Why retailers sell private labels," Journal of Economics \& Management Strategy, vol. 4, no. 3, pp. 509-528, 1995.

[35] C. Narasimhan and R. Wilcox, "Private labels and the channel relationship: a cross-category analysis," The Journal of Business, vol. 71, no. 4, pp. 573-600, 1998.

[36] H. Kurata, D.-Q. Yao, and J. J. Liu, "Pricing policies under direct vs. indirect channel competition and national vs. store brand competition," European Journal of Operational Research, vol. 180, no. 1, pp. 262-281, 2007.

[37] S. Karray and G. Martin-Herran, "A dynamic model for advertising and pricing competition between national and store brands," European Journal of Operational Research, vol. 193, no. 2, pp. 451-467, 2009.

[38] H. S. Heese, "Competing with channel partners: supply chain conflict when retailers introduce store brands," Naval Research Logistics, vol. 57, no. 5, pp. 441-459, 2010.

[39] F. Scott Morton and F. Zettelmeyer, "The strategic positioning of store brands in retailer-manufacturer negotiations," Review of Industrial Organization, vol. 24, no. 2, pp. 161-194, 2004.

[40] A. Groznik and H. S. Heese, "Supply chain interactions due to store-brand introductions: the impact of retail competition," European Journal of Operational Research, vol. 203, no. 3, pp. 575-582, 2010.

[41] W. Chu and P. Desai, "Channel coordination mechanisms for customer satisfaction," Marketing Science, vol. 14, no. 4, pp. 343359, 1995.

[42] A. Coughlan, "Competition and cooperation in marketing channel choice: theory and application," Marketing Science, vol. 4, no. 2, pp. 110-129, 1985.

[43] X. Vives, Oligopoly Pricing: Old Ideas and New Techniques, The MIT Press, Cambridge, Mass, USA, 2001. 


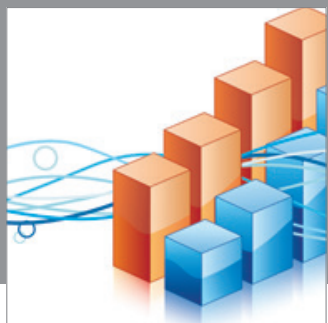

Advances in

Operations Research

mansans

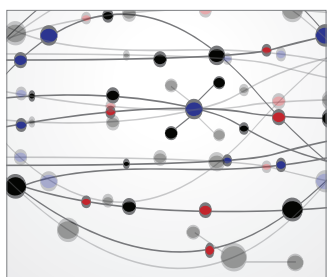

The Scientific World Journal
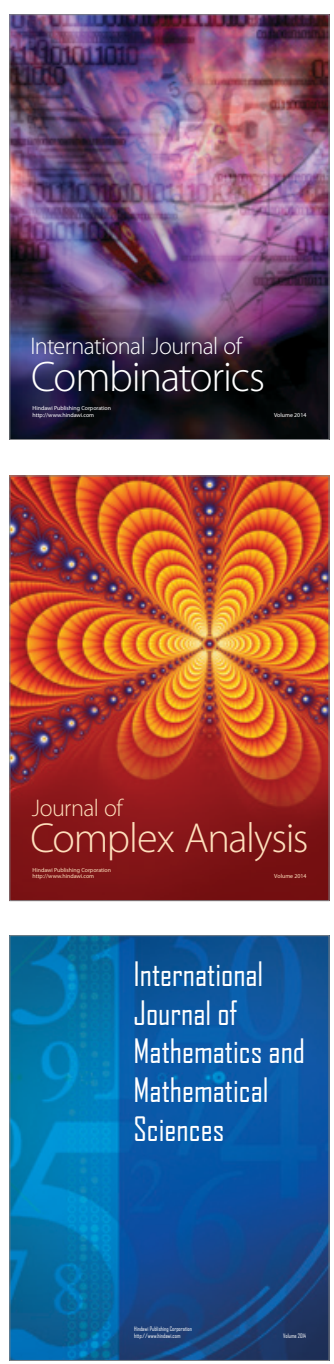
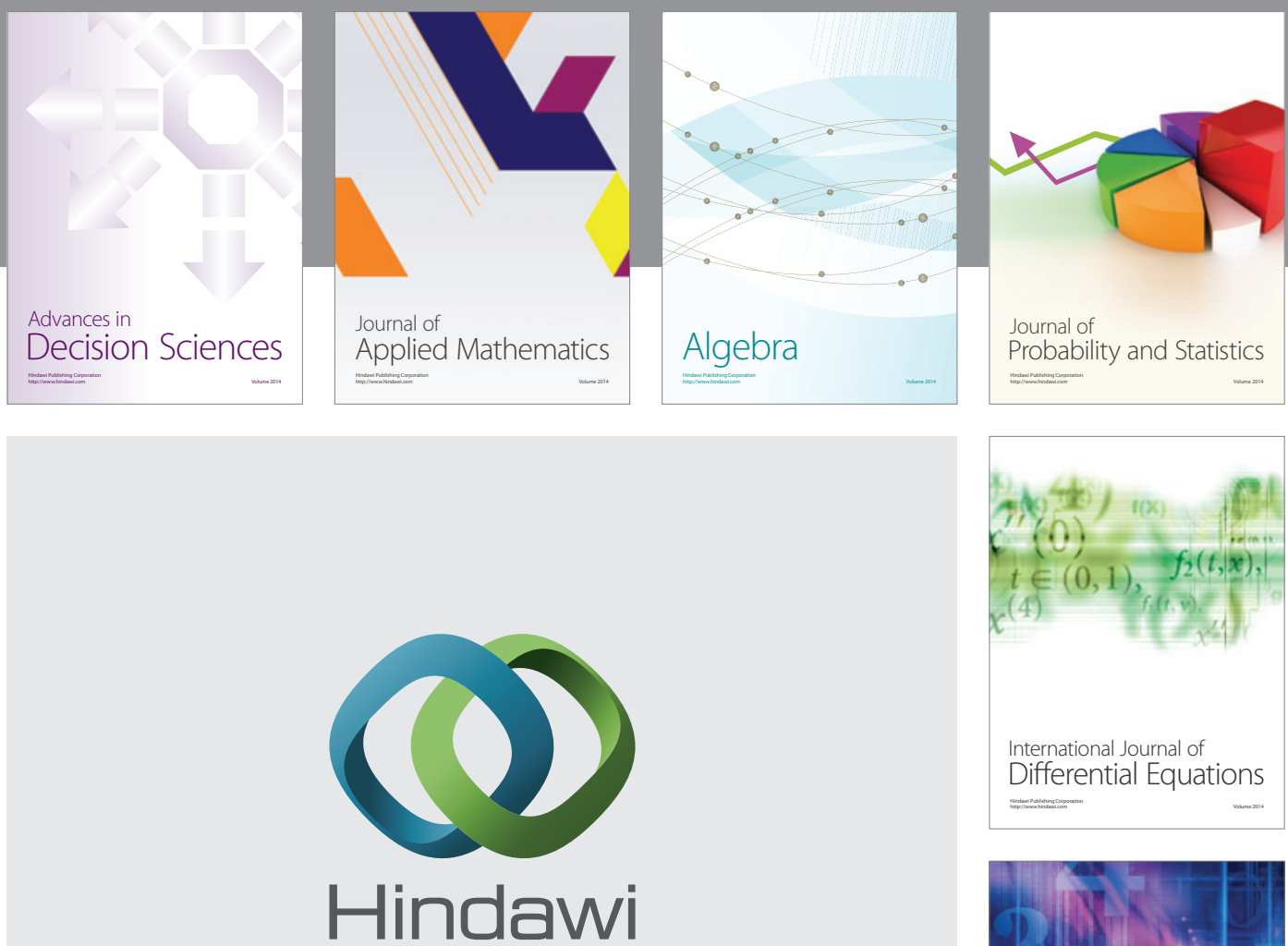

Submit your manuscripts at http://www.hindawi.com
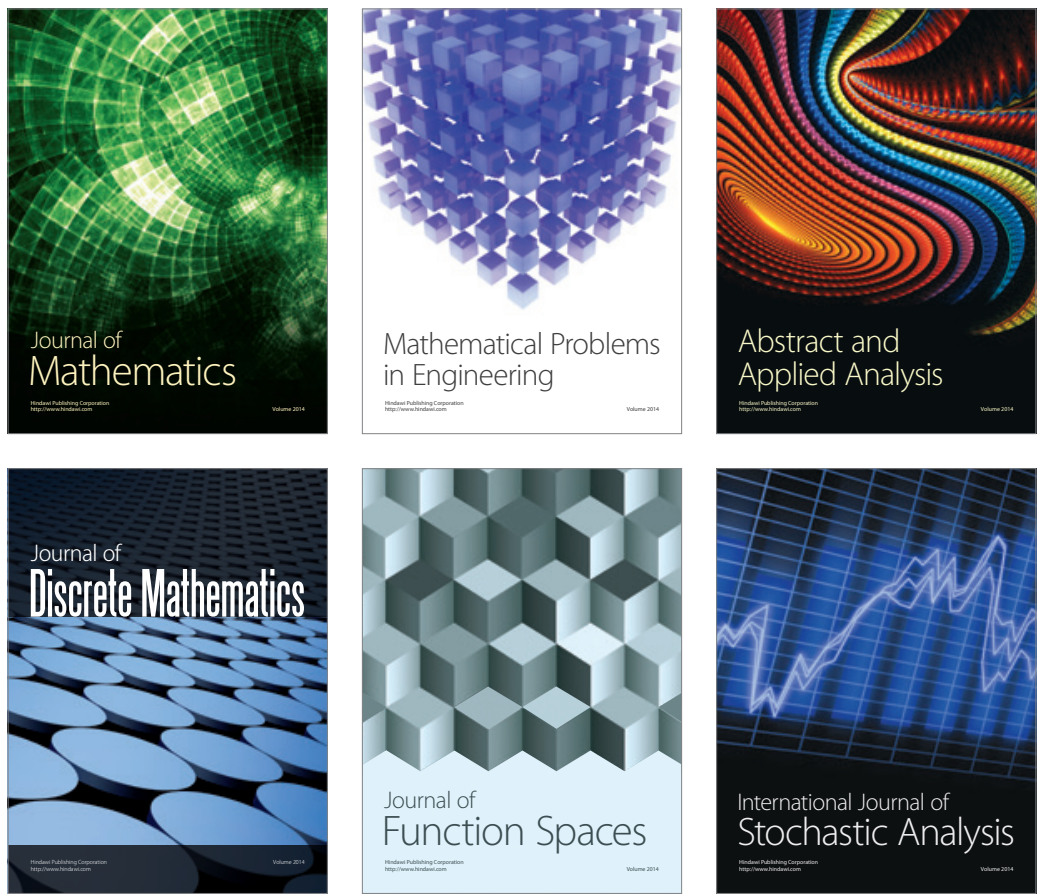

Journal of

Function Spaces

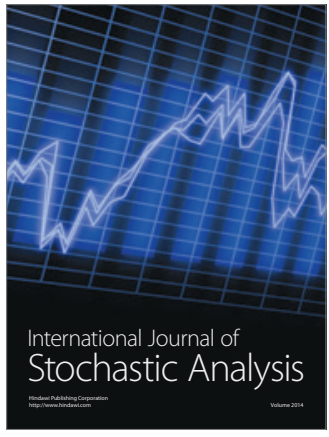

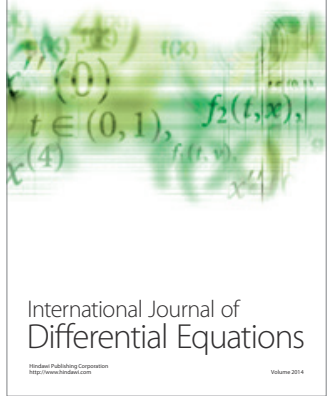
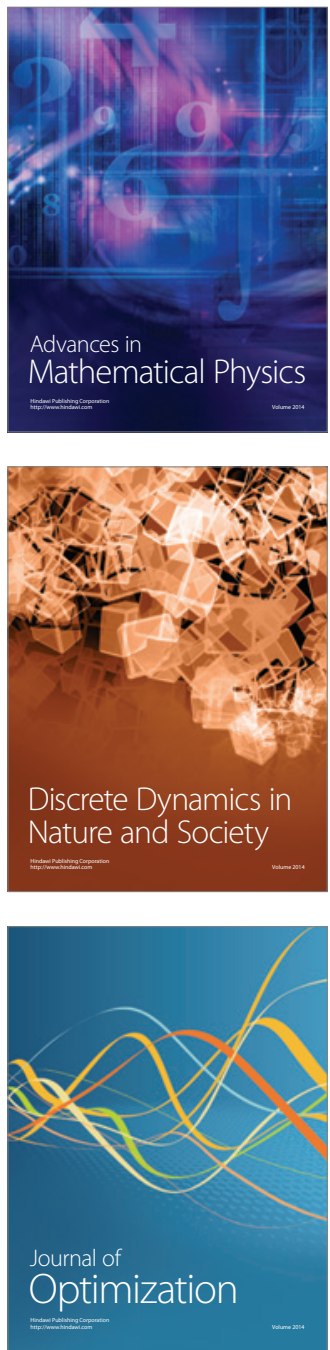